\title{
Incorporation of nano-metal particles with paper matrices
}

\author{
Abeer M.Adel* \\ National Research Center, Cellulose and Paper Department, 33 El-Bohouth St. (Former El-Tahrir St.), Dokki, Giza, Egypt. P.O. 12622
}

\begin{abstract}
The upraising value of nano-metal particles is increasing from one day to another due to its wide usage in enormous range of applications in several fields. This high value is due to the new approaches of the nano-metal science which enabled the researchers to improve the characteristics of these nano-metal particles through some processes of incorporation of nano-metal particles on the different cellulosic fibers substrates. One of these substrates is the paper fibers which is a natural polymer. Nano-metal particles retention may occur in case of incorporation of the nano metal particles in the paper fibers substrate. The adherence to the paper fibers matrices via weak interactions like Van der Waals force would lead to weak retention. Raising the retention may take place through incorporating nano-metal particles in paper matrices by adding suitable linkers, binders, or retention aids. While these substances improve the retention and the strength properties of paper sheets, however they add extra cost to the final product. Also addition of these retention aids and linkers restrict the active sites availability in the nano-metal particles, which in turn decreases the applicability of these nano metal particles in some applications. More modern hydrothermal method was used to incorporate nano-metal particles in paper matrices in a single step without adding any binders, linkers or retention aids (in situ). The purpose of this state of art is to present and discuss; the main synthesis methods of nano-metal particles, principal characteristics and different attachment methods of nano-metal particles.
\end{abstract}

\section{Introduction}

The upraising which deals with materials with size of up to about $100 \mathrm{~nm}$ in one or more dimensions, provided great opportunities for the progress of materials with new properties for use in new applications. Recently, the interest of the nano-sized inorganic compounds has been widely increased due to its strong antibacterial activity at low concentrations. This antibacterial behavior is due to the high surface area to volume ratio and splendid chemical and physical properties of these compounds [1]. In addition, these compounds are more stable in drastic conditions such as; high temperatures and pressures. Some of these compounds are nontoxic and even contain mineral elements which are essential to the human body. Most antibacterial inorganic materials are metallic nanoparticles and metal oxide nanoparticles such as gold, silver, copper, titanium oxide and zinc oxide [2]. The optical, electronic, conductivity, catalytic and antimicrobial properties of the metal oxide nanoparticles $\left(\mathrm{TiO}_{2}, \mathrm{ZnO}, \mathrm{Fe}_{2} \mathrm{O}_{3} / \mathrm{Fe}_{3} \mathrm{O}_{4}, \mathrm{CuO}, \mathrm{Ag}\right.$ and $\mathrm{Au}$ ) represented an advantage to be used in enormous applications in different fields like piezoelectric, magnetic, gas sensor, and dye sensitized solar cells.

The increase of pollutant levels due to industrialization and repetition of infectious diseases caused by different microorganisms become a serious threat to the human health and the environment. Researchers have exerted a lot of efforts to find low cost- efficient systems to purify water and air via degradation of these contaminants [3]. Nano-metal particles like $\mathrm{TiO}_{2}, \mathrm{ZnO}, \mathrm{Fe}_{2} \mathrm{O}_{3} / \mathrm{Fe}_{3} \mathrm{O}_{4}, \mathrm{Bi}_{2} \mathrm{O}_{3}$, and $\mathrm{CuO}$ could be a great solution to face these hazards by using them as photocatalysts to degrade organic compounds, as well as, for their antimicrobial effect [4].

$\mathrm{TiO}_{2}$ has the ability to exchange energy from light to chemical redox energy. Whereas, on $\mathrm{TiO}_{2}$ surfaces there are two kinds of photochemical reactions take place, photo-induced redox reaction and photo-induced hydrophilic conversion upon UV irradiation as presents in Figure 1 and 2 [5,6].

The accurate mechanism of nano-metal particles action on microorganisms is still unknown. However, the antimicrobial effect of $\mathrm{ZnO}$ nano-metal particles is assigned to several mechanisms including the release of antimicrobial ions, interaction of nano-metal particles with microorganisms, subsequently damaging the integrity of bacterial cell and the formation of reactive oxygen species by the effect of light rays (Figure 3) [7].

Nano-metal particles can be recovered from treated solutions by using centrifugation, filtration, or sedimentation. These nano-

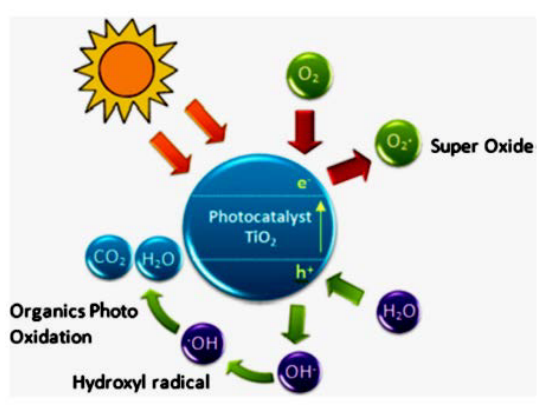

Figure 1. Photo-induced redox reaction of $\mathrm{TiO}_{2}$.

Correspondence to: Abeer M. Adel, National Research Center, Cellulose and Paper Department, 33 El-Bohouth St. (Former El-Tahrir St.), Dokki, Giza, Egypt. E-mail: abeermadel2003@yahoo.com

Received: September 17, 2016; Accepted: October 17, 2016; Published: October 20, 2016 


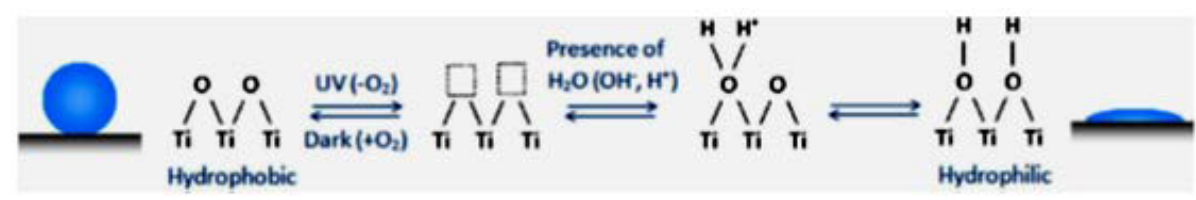

Figure 2. Photo-induced hydrophilic and hydrophobic conversion of $\mathrm{TiO}_{2}$

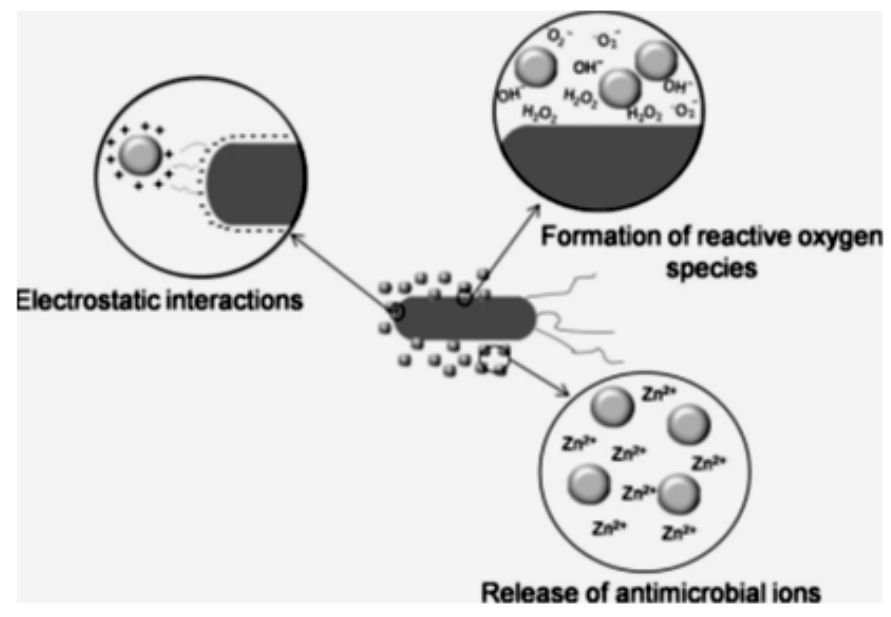

Figure 3. Different mechanisms of antimicrobial activity of $\mathrm{ZnO}$ nanoparticles (represented by gray spheres).

metal particles can be obtained by incorporating them on various substrates such as ceramics, glass, polymers, cellulose fibers, and paper, however, each substrate has its own advantage and disadvantage $[8,9]$. Paper matrices can be considered as superior alternative to other substrates since it is biodegradable, biocompatible, cost effect and renewable [10]. Also, due to the porous structure and hydrophilicity of fiber surface, paper matrices can absorb suspension of nano-metal particles via capillary forces leading to higher loading of nano-metal particles. Moreover, small volume of nano-metal particles deposited on paper sheets can be used in different devices which gives optical [11], antimicrobial [12], anti-counterfeiting [13], surface enhanced raman scattering [14] and surface plasmon resonance [15]. However, paper has some disadvantages such as low strength properties and deteriorates of mechanical properties under moist environments.

The aim of this state of art is to present and discuss; the main synthesis methods of nano-metal particles, principal characteristics and different attachment methods of nano-metal particles.

\section{Synthesis of nano-metal particles}

Nano-metal particles can be synthesized by three main approaches; the physical approach which utilizes several methods such as; evaporation/condensation and laser ablation. The chemical approach, where metal ions solution is reduced in conditions that motivating the consequent formation of small metal clusters or aggregates. Finally, the combination of inorganic nano-metal particles and biological structures is also a favorable technique where no toxic chemicals are used [16].

Chemical methods can be classified in terms of the nature of the reducing agents to classical chemical, using the famous chemical reducing materials e.g. hydrazine, sodium borohydride, hydrogen, etc. and radiation-chemical where solvated electrons generated by

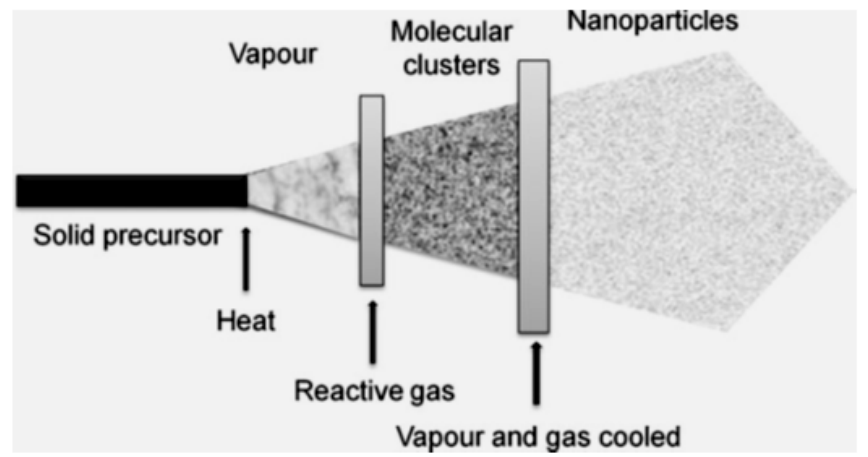

Figure 4. Physical vapor synthesis of nano-metal particles.

the ionizing radiation starts the reduction process [17]. Moreover, chemical methods can be classified in terms of using non-deleterious solvent and naturally occurring reducing agent e.g. polysaccharides or plants extract or biological micro-organism e.g. bacteria and fungus as reductions materials [18]. Stabilization of nano-metal is always discussed in terms of electrostatic and steric stabilization. Electrostatic stabilization is the coordination of anionic species, e.g. halides, carboxylates or polyoxoanions, to metal particles which leads to the formation of an electrical double layer. This double layer results in columbic repulsion force between the nano-metal particles. On the other hand, steric stabilization may occur due to the presence of bulky, typically organic materials that, due to their bulk, hinder the nanoparticles from diffusing together. Polymers and large cations like alkylammonium are examples of steric stabilizers [19].

\section{Physical methods}

\section{Physical vapor synthesis}

One of the methods to produce nano-metal particles is the physical vapor synthesis where a solid precursor is exposed to a plasma arc energy which in turn produce vapor at high temperature (Figure 4). When the precursor is injected into the plasma, the energy plasma arc's energy induces the super-saturation and particle nucleation of the precursor. The particles are formed due to the reaction and/or condensation of the precursor' atoms by mixing with cool gas or by expansion through a nozzle. Finally, the resulting nano-metal particles are provided due to the addition of a reactant gas to the vapor followed by cooling at a controlled rate and then condensed, the sizes of the formed particles are ranged in average from 8 to $75 \mathrm{~nm}$ [20].

\section{Pulsed laser ablation}

Pulsed laser ablation method is one of the major irradiation approaches used to produce nano-metal particles. For example, laser irradiation is used to generate Ag nano-metal particles with a well-defined shape and size distribution by irradiating an aqueous solution of Ag salt and surfactant. Laser is also applied in a photosensitization procedure for the synthesis of Ag nano-metal particles using benzophenone, where, low laser powers at short irradiation times 
produced Ag nano-metal particles of $\sim 20 \mathrm{~nm}$ and high irradiation produced gave nanoparticles of $\sim 5 \mathrm{~nm}[21]$.

\section{Microwave irradiation}

This procedure is an extra-active and easy approach with low time of reaction for preparation of nano-metal particles. Microwave radiation can successfully generate thinner particle sizes in shorter reaction time in comparison of the classical heating system due to homogenous fast heating [22]. However, in case of the microwave irradiation energy transfer to the materials is due to the interaction between the microwaves energy with water (or other solvents with high dielectric constant or solvents molecules with large dipole moments). Gouda, et al. studied in situ preparation of nano-metal particles on the thiol-modified cotton fabric [23]. Before the synthesis of nano-metal particles started, the thiol-modified cotton fabrics chelated with metal salt were prepared. This was done by dipping the modified cotton fabrics into a conical flask containing solution of $\mathrm{FeCl}_{3}, \mathrm{CuCl}_{2}, \mathrm{CoCl}_{2}$, and $\mathrm{MnCl}_{2}$ solutions separately. Modified cotton fabrics containing metal salts were then subjected to microwave irradiation at $100^{\circ} \mathrm{C}$ for $5 \mathrm{~min}$ to get nano-metal oxides such as iron oxide, copper oxide, cobalt oxide, and manganese into thiol-modified cotton fabric.

\section{Gamma radiation}

Gamma radiation has been established a simple and efficient technique for nano-metal particles production. The synthesis of nanometal particles through the gamma radiation route requires an aqueous system, room temperature and ambient pressure. In this method, the aqueous solution of metal salt is exposed to $\gamma$-rays. The species hydrated electron and hydrogen atoms rising from radiolysis of water are strong reducing agents and they reduce the metal ion to zero valent state [24].

$$
\mathrm{H}_{2} \mathrm{O} \stackrel{\text { yirradiation }}{\longrightarrow} e^{-}{ }_{a q}, \mathrm{H}_{3} \mathrm{O}^{+}, \mathrm{H}^{\bullet}, \mathrm{OH}^{\bullet}, \mathrm{H}_{2}{ }^{\cdot}, \mathrm{H}_{2} \mathrm{O}_{2}^{\cdot}
$$

\section{Sonochemical synthesis of nano-metal structure}

Ultrasonic irradiation of aqueous liquids e.g. water generates frees radicals. The sonolysis products in water are $\mathrm{H}^{-}$and $\mathrm{OH}^{-}$radicals. These radicals can recombine to return to their original form or combine to produce $\mathrm{H}_{2}$ and $\mathrm{H}_{2} \mathrm{O}_{2}$. They also can produce $\mathrm{HO}_{2}{ }^{\circ}$ by combination with $\mathrm{O}_{2}$. These strong oxidants and reductants are mainly used in different sonochemical reactions in aqueous mediums. Sonochemistry is advantageous in two aspects; the use of less volatile organic solutions and the ability to provide different forms of nanostructured metals simply by changing reaction conditions e.g. oxides, sulfides and carbides [25].

\section{Metals}

Sonochemical reduction of noble metal salts (e.g., $\mathrm{Au}, \mathrm{Ag}, \mathrm{Pt}$, and $\mathrm{Pd}$ ) is favorable more than other classical reduction methods (e.g., sodium borohydride, hydrogen, and alcohol) where, no chemical reducing agent is required. The reaction is characterized by its fast rate and its resultant fine metal particles [26]. As discussed before, water sonolysis is the main reason for the sonochemical reductions where the generated $\mathrm{H}^{*}$ radicals act as reductants. Frequently, organic additives (e.g., 2-propanol or surfactants) are used to provide a secondary radical species, which is significantly promoting the reduction rate:

$$
\begin{aligned}
& \mathrm{H}_{2} \mathrm{O} \longrightarrow \mathrm{H}^{\bullet}+\mathrm{OH}^{\bullet} \\
& H^{\bullet}+H^{\bullet} \longrightarrow H_{2} \\
& \mathrm{H}^{\bullet}+\mathrm{OH}^{\bullet} \longrightarrow \mathrm{H}_{2} \mathrm{O} \\
& \mathrm{RH}+\mathrm{OH}^{\bullet}\left(\mathrm{orH}^{\bullet}\right) \longrightarrow \mathrm{R}^{\bullet}+\mathrm{H}_{2} \mathrm{O}\left(\mathrm{orH}_{2}\right) \\
& \mathrm{OH}^{\bullet}+\mathrm{OH}^{\bullet} \longrightarrow \mathrm{H}_{2} \mathrm{O}_{2} \\
& A u(I I I)[\operatorname{Ag}(I), P t(I I), \operatorname{orPd}(I I)]+H^{*} \operatorname{orR}^{*} \longrightarrow \operatorname{Au}(0)[\operatorname{Ag}(0), \operatorname{Pt}(0), \operatorname{orPd}(0)] \\
& n M(0) \longrightarrow M_{n}(M=\text { noblemetal })
\end{aligned}
$$

\section{Metal oxides}

Preparation of different forms of metal oxides nanostructured through the sonication takes place using an aqueous metal salt solution under ambient conditions (usually in the presence of air). Sonochemical process is advantageous over other traditional methods while producing metal oxides due to the better uniform size distribution, higher surface area, faster reaction time, and improved phase purity of the produced metal oxides. Different examples of successful sonochemical syntheses have been recognized e.g. $\mathrm{TiO}_{2}$ [27], $\mathrm{ZnO}$ [28], $\mathrm{CeO}_{2}$ [29] and $\mathrm{MoO}_{3}$ [30].

\section{Chemical methods}

\section{Mechanochemical process}

The process is used to synthesize the different nano-metal particles including $\mathrm{ZnS}, \mathrm{CdS}, \mathrm{ZnO}, \mathrm{SiO}_{2}$ and $\mathrm{CeO}_{2}$ [31]. In this process, the nano-metal particles are provided through the combination of physical size reduction process in a conventional ball mill and chemical reactions that are mechanically activated at the nano-scale during grinding. Using this process to prepare crystalline $\mathrm{ZnO}$ nanoparticles, the precursors zinc chloride $\left(\mathrm{ZnCl}_{2}\right)$ and sodium carbonate) $\mathrm{Na}_{2} \mathrm{CO}_{3}$ ) are successively milled in a ball mill which results zinc carbonate $\left(\mathrm{ZnCO}_{3}\right)$ and sodium chloride $(\mathrm{NaCl})$ (Figure 5). An inert diluent $(\mathrm{NaCl})$ is added to the precursors which produces a nano-composite, with $\mathrm{NaCl}$ acting as the matrix phase. The starting materials mixture has the following chemical reaction:

$$
\mathrm{ZnCl}_{2}+\mathrm{Na}_{2} \mathrm{CO}_{3}+8 \mathrm{NaCl} \longrightarrow \mathrm{ZnCO}_{3}+10 \mathrm{NaCl}
$$

The produced nano-metal composite is heated at $\left(170-380^{\circ} \mathrm{C}\right)$ for the thermal decomposition of $\mathrm{ZnCO}_{3}$ to $\mathrm{ZnO}$, and then washed

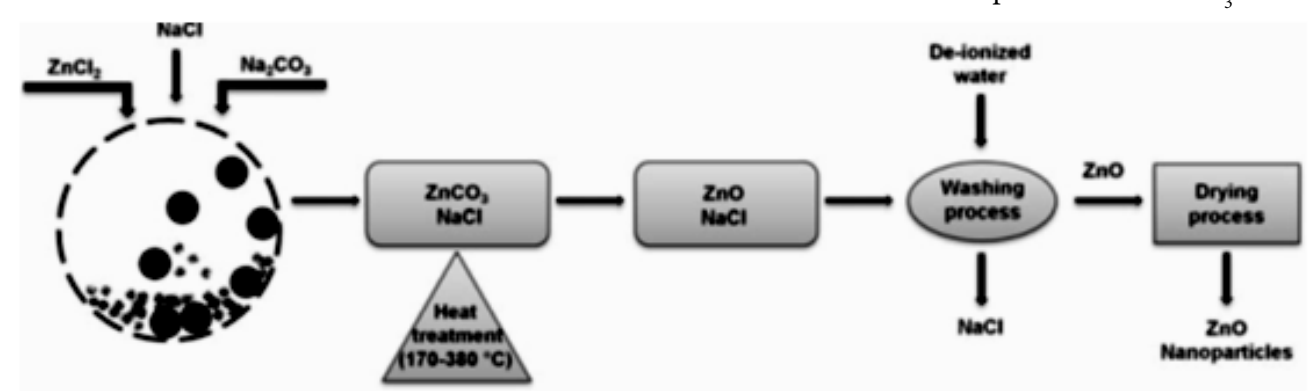

Figure 5. Mechanochemical processing for $\mathrm{ZnO}$ nanoparticle synthesis. 
to separate the $\mathrm{NaCl}$ from $\mathrm{ZnO}$ and finally dried. The average sizes of the produced nano-metal particles are ranged from 20 to $30 \mathrm{~nm}$. The produced nano-metal particles size depends mainly on the milling time and temperature. Increasing the milling time can effectively reduce the size of the nano-metal particles, where, increasing the temperature increases the size of the nano-metal particles [32].

\section{Polysaccharide method}

The thermodynamic instability of the nano-metal particles and their tendency to aggregate ease their aggregation in a bulk metal even in the absence of capping agents, ligands or supports. Due to the high surface area, reductive functional groups and water suspend-ability of the nanocelluloses, they considered attractive supports for nano-metal particles. Three main approaches are used to prepare the nano-metal particles as shown in (Figure 6);

a. Reduction via an external reducing agent: In this approach, a reduction process of the metal precursor to metal nanoparticles on the nanocellulose surface using an external reducing agent is taken place. Different examples will be presented as follow to demonstrate how much the process is common;

Ag nanoparticles were produced on different types of nanocelluloses by reducing $\mathrm{AgNO}_{3}$ with $\mathrm{NaBH}_{4}$ [33]. Different external reducing agents e.g. triethanolamine, $\mathrm{NH}_{2} \mathrm{NH}_{2}, \mathrm{NH}_{4} \mathrm{OH}$ and ascorbic acid can be used to reduce $\mathrm{Ag}$ salts to $\mathrm{Ag}$ nanoparticles [34]. Au nanoparticles were produced from $\mathrm{HAuCl}_{4}$ on the nanocelluloses using $\mathrm{NaBH}_{4}$ and poly (ethyleneimine) as external reducing agents [35] [36]. Borohydride reduction has also taken place in producing $\mathrm{Pd}, \mathrm{Ru}, \mathrm{CuO}$ and alloy nanoparticles, including $\mathrm{Au}-\mathrm{Pd}, \mathrm{Pd}-\mathrm{Cu}$, and $\mathrm{Au}-\mathrm{Ag}$ [37].

b. Reduction via modified nanocellulose surface: In this a process, a surface modification for the nanocellulose is taken place, to act as bio-templates for the nano-metal particles, by attaching chemical groups that have reducing/coordinating capabilities. These modified nanocellulos are used to produce nano-metal particles from their corresponding salts, without any external reducing agent, e.g. smart conductive textiles were produced by the synthesizes of nanocarbamoylethyl cellulose as precursors to produce nano-metal particles [38]. The produced silver nano-metal particles have; small sizes, spherical shape and high stability up to concentration as high as 2000 ppm as indicated by UV spectroscopy and transmission electron microscopy (TEM). Accordingly, Ag nano-metal particles were utilized effectively as highly functional, effective and suitable precursor to get smart conductive textiles.

Periodate oxidized nanocellulose were also employed in the formation of $\mathrm{Ag}$ nano-metal particles from $\mathrm{Ag}(\mathrm{I})$ salt, where the aldehyde groups on the nanocellulose surface act as reducing agents [39]. Au nanoparticles were also produced from their metal salt using surface-modified nanocelluloses as reducing agents such as; grafted PAMAM poly (amidoamine)-dendrimer onto cellulose nanocrystals, and the amine groups were used for reducing $\mathrm{HAuCl}_{4}$ into $\mathrm{Au} \mathrm{NPs} \mathrm{[40].}$

c. Reduction via nanocelluloses: In this approach, the surface hydroxyl groups on the nanocelluloses are used as a reducing agent for the metal precursors to form the nano-metal particles. The nanocelluloses act as both support and reducers for the generation of nano-metal particles, $\mathrm{Ag}, \mathrm{Au}, \mathrm{Pd}, \mathrm{Pt}, \mathrm{Fe}_{2} \mathrm{O}_{4}, \mathrm{Fe}_{3} \mathrm{O}_{4}, \mathrm{Ni}$ and $\mathrm{ZnO}$ nanoparticles were synthesized via hydrothermal procedures [37, 41].

\section{Sol-gel technique}

Lately, there has been an increase of research into the production of nanoparticles via sol-gel techniques. This reaction scheme produces nanoparticles, usually metal oxides, through the use of a gel matrix to control the mixing of precursors. The reaction usually involves the integration of solution of metal alkoxides (sol) into a polymer (gel). Once the precursors are incorporated into the matrix, they undergo a hydrolysis reaction which forms the product. The final step of the reaction is calcination of the sol-gel, which causes the agglomeration of the particles, and usually results in causing polydispersity, depending on heating temperature and duration. The following scheme represents the preparation process as shown in (Figure 7) [42].

\section{Microemulsion technique}

The microemulsion is a thermodynamic stable, optical isotropic solution of two immiscible liquids stabilized by an interfacial film of surfactant. Microemulsion is a micro-heterogeneous medium that generates the nano-metal particles, which is controlled by the reactant distribution in the droplets and by the dynamics of inters

a) Reduction using an external agent

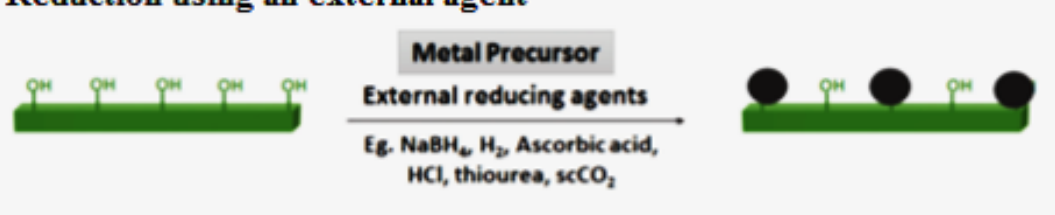

b) Reduction via modified nanocellulose

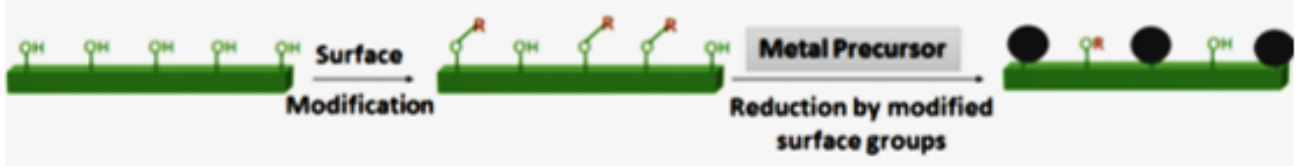

c) Reduction using nanocelluloses
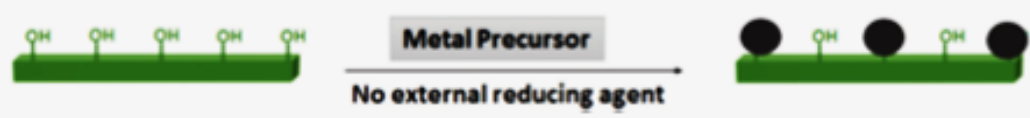

Figure 6. Three approaches for synthesis of metal NP-nanocellulose hybrid composite: (a) reduction using an external agent, (b) reduction via modified nanocellulose surface, and (c) reduction using nanocelluloses 


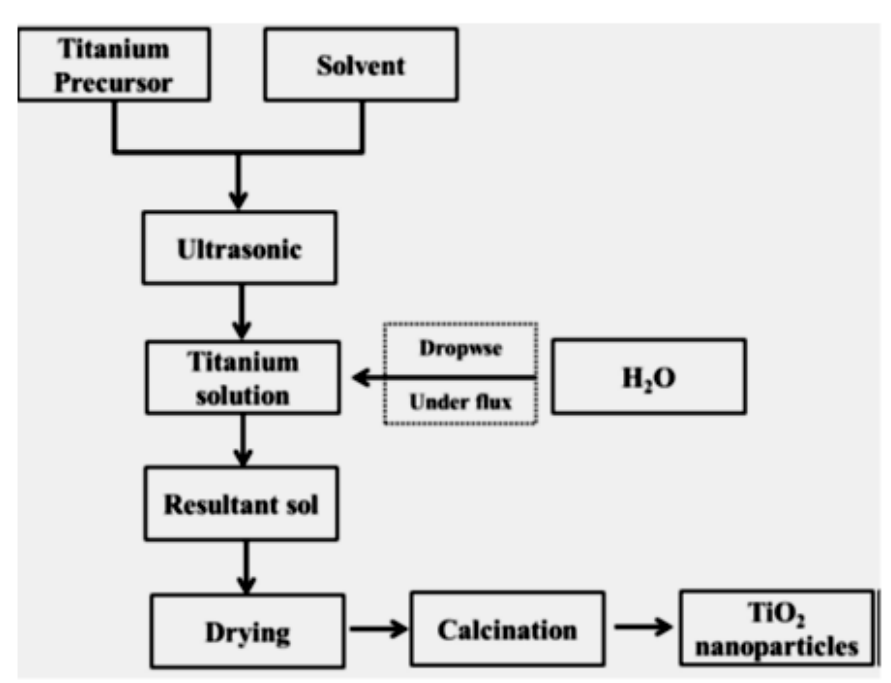

Figure 7. Scheme of the preparation of $\mathrm{TiO}_{2}$ nanoparticles sol-gel.

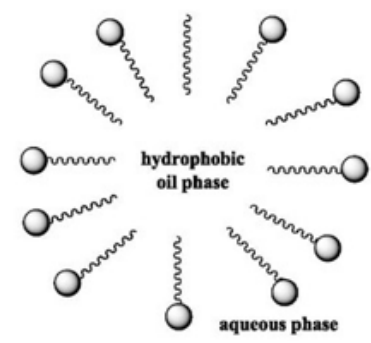

(a)

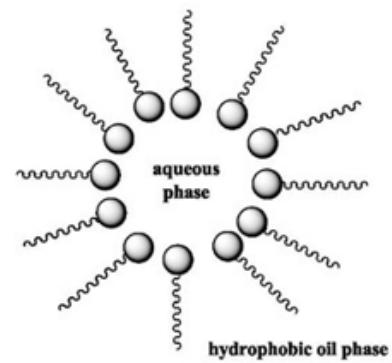

(b)
Normal micelles

Reverse micelles

Figure 8. Normal micelle and Reverse micelle structures.

droplet exchange of reactants. The surfactant-stabilized micro-cavities provide a cage-like effect which limits particle nucleation, growth and agglomeration [43]. The microemulsion occurs in two phases: $\mathrm{O} / \mathrm{W}$ (oil in water) and $\mathrm{W} / \mathrm{O}$ (water in oil) which are similar to aqueous and non-aqueous mediums, respectively. The micelles are formed in aqueous medium, where the surfactants' hydrophobic hydrocarbon chains are oriented toward the interior of the micelle, and the surfactants' hydrophilic groups are in contact with the surrounding aqueous medium. In contrary, reverse micelles are formed in nonaqueous medium, where the hydrophilic head groups are directed toward the core of the micelles, where, the hydrophobic groups are directed outward (Figure 8). The stability of the emulsions is related to; the particle size, particle-particle interaction, particle water interaction and particle-oil interaction [44].

\section{Precipitation}

Precipitate formation from a homogeneous liquid phase is due to the physical process (temperature change, $\mathrm{pH}$, evaporation of the solvent, concentration of the reactant, etc.) and/or chemical process (addition of acids or bases, use of complex forming agents). In all cases, the formation of a new solid phase in a liquid medium is due to two instant processes; (i) nucleation, which is the formation of the smallest elementary particles of the new stable phase under the precipitation conditions; and (ii) particles' growth or agglomeration. Nano-metal particles with narrow size distributions can be synthesized through controlling the precipitation factors such as; the $\mathrm{pH}$, concentration of the reactants/ions. Oxides synthesis of, co-precipitation method includes precipitation of hydroxides by the addition of a solution e.g. $\mathrm{NaOH}, \mathrm{NH}_{4} \mathrm{OH}$, urea, etc. to the reactant followed by heat treatment e.g. calcination to crystallize the oxide [45].

\section{Hydrothermal method}

Water in hydrothermal method plays two roles as a catalyst and occasionally as a component of solid phases (high temperature $>100^{\circ} \mathrm{C}$ \& pressure, more than a few bars). This technique produces monodispersed and highly homogeneous nano-metal particles, and also used to process nano-hybrid and nano-composite materials widely used in the ceramics industry [46].

One of the examples for the hydrothermal methods is the preparation of $\mathrm{TiO}_{2}$ ultrafine powders from metallic $\mathrm{Ti}$ by the hydrothermal $\mathrm{H}_{2} \mathrm{O}_{2}$ oxidation process. The process occurred in two steps; first step is the oxidation of Ti with an aqueous solution of $\mathrm{H}_{2} \mathrm{O}_{2}$ and ammonia to form a gel $\left(\mathrm{TiO}_{2}, \mathrm{H}_{2} \mathrm{O}\right)$ and the second step is the hydrothermal treatment of gel under several conditions [47].

\section{Solvothermal method}

Similarly to the hydrothermal process, the solvothermal method is typically following the same process except that water is replaced by organic solvents. This process is considered a transformation or chemical reaction in an organic solvent e.g. methanol, 1, 4- butanol, toluene under supercritical pressure and temperature. Solvothermal processing provides high chemical homogeneity and the possibility of deriving unique metastable structures at low reaction temperatures [48].

\section{Electrochemical process}

The electrochemical process is a six steps technique starting by oxidative dissolution of the sacrificial Mbulk anode followed by the migration of $\mathrm{Mn}+$ ions to the cathode then reductive formation of the zero valent metal atoms at the cathode takes place. In consequence, formation of metal particles by nucleation and growth occur. Finally, the colloidal protective agents (like tetra alkyl ammonium ions) stop the growth and stabilize the particles which lead to the precipitation of the nano-metal structured colloids (Figure 9) $[49,50]$.

$$
\text { Anode: } \quad M_{\text {bulk }} \longrightarrow M^{n+}+n e^{-}
$$

Cathode: $\quad M^{n+}+n e^{-}+$stabilizer $\longrightarrow M_{\text {coll }} /$ stabilizer

Sum: $M_{\text {bulk }}+$ stabilizer $\longrightarrow M_{\text {coll }} /$ stabilizer

\section{Biological synthesis}

The reaction between inorganic nanoparticles and biological structures can give inorganic materials either intra- or extra-cellular. Microorganism is an eco-friendly method for preparing nano-metal particles under moderate conditions with no need for toxic chemicals in the synthesis process [51]. The provided nano-metal particles through using bacteria show considerable polydispersity since the size of nano-metal particles is affected by; bacteria cell growth, incubation solution composition, and metals growth conditions. However, monodispersed products can be synthesized by the adjust control of the synthetic parameters (concentration, $\mathrm{pH}$, temperature, etc.) [52], in the same way, fungi and yeasts can produce nano-metal particles through the microbial processes [53].

\section{Characterization of nano-metal particles}

Nano-metal particles characterization can be fulfilled using different techniques like transmission and scanning electron microscopy (TEM, 


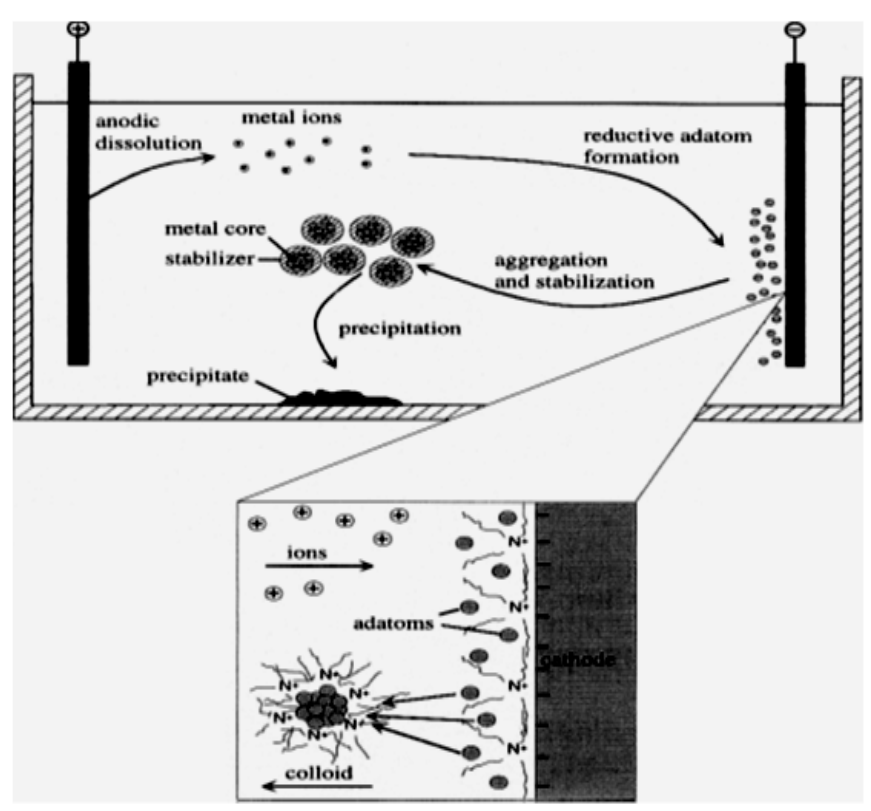

Figure 9. Electrochemical formation of $\mathrm{NR}_{4}^{+} \mathrm{Cl}^{-}$stabilized nano-metal.

SEM), atomic force microscopy (AFM), dynamic light scattering (DLS), X-ray photoelectron spectroscopy (XPS), powder X-ray diffraction (XRD), Fourier transform infrared spectroscopy (FTIR), and UV spectroscopy. These characterization parameters to be investigated are; particle size, shape, crystallinity, fractal dimensions, pore size and surface area. In addition, orientation, intercalation and dispersion of nano-metal particles and nanotubes in nano-composite materials can be investigated by the same techniques. [54].

\section{Attachment methods of nano-metal particles to paper matrices}

The incorporation of nano-metal particles on paper matrices can take place either by wet end addition and surface treatment methods;

\section{Wet-end addition}

In the wet-end addition method, the nano-metal particles incorporated into separate fibers before paper sheet formation. Commercial powders in nano-sized are applied as fillers in manufacturing of paper to get an improvement in smoothness, thermal stability, gloss, optical, and other paper matrices properties. These fillers were incorporated to cellulose fibers by weak bonds as hydrogen bonds and Van der Waals forces. So, retention can be improved in the final product by adding binders, linkers and retention aids during paper making. These different additives were used to improve the adherence of the nano-metal particles in paper fibers. In this part, various methods have been used to incorporate nano-metal particles in paper matrices [55].

One of the most common filler in the paper manufacture is $\mathrm{TiO}_{2}$, it is widely used in particular in photocatalytic reactions due to its novel optical properties; photo stability, abundance, and affordable price [56].

Wet-end addition method was used to produce photocatalytic papers made from $\mathrm{TiO}_{2}$ supported by ceramic fibers, which resulted in a higher photocatalytic property than $\mathrm{TiO}_{2}$ powder and $\mathrm{TiO}_{2}$-pulp mixture [57].
Preparation of core-shell pigments containing titanium dioxide/ calcium carbonate $\left(\mathrm{TiO}_{2} / \mathrm{CC}\right)$ symbolized $\mathrm{CT} 1$ and $\mathrm{CT} 2$ according to the thickness of the $\mathrm{TiO}_{2}$ shell were applied as filler in paper matrices. The results indicated that, adding $15 \%$ CT1 increased the retention (40.77\%), but it was less than that of CT2 (55.14\%). Because of the highest filler retention of calcium carbonate CC, titanium dioxide, core shell pigments CT1 and CT2, an improvement in brightness and opacity of the paper sheets occurred. The incorporation of $\mathrm{CC}, \mathrm{TiO}_{2}$, CT1 and CT2 pigments in paper sheet improved the breaking length, while the burst and tear indices were similar to that of unpigmented paper this is related to the incorporation of pigments in the fiber matrices [58].

\section{Surface treatment}

The surface treatment technique is extremely important in case of using the nano-metal particles as a coat on the cellulosic fiber substrate, since the crystalline properties of the coated substrate varied according to the shape and the nature of the coated surface. In the surface treatment method, paper sheets are embedded with nanometal particles through a bath of chemicals which was used to coat or impregnate paper surface.

The incorporation of nano-metal particles into paper matrices were controlled by hydrophobicity (sizing) and porosity. The most common surface treatments to coat nano-metal particles onto paper matrices are; size press, layer by layer deposition, sol-gel method, direct and in situ assembly.

\section{Size-press treatment}

Size press process was used to produce photocatalytic papers by coating of paper sheets with a mixture of $\mathrm{TiO}_{2}$ and different kinds of binder such as colloidal silica, resin and silicon binders. These binders have the ability to incorporate $\mathrm{TiO}_{2}$ into paper matrices and maintain paper from photo-degradation. A mixture of $\mathrm{TiO}_{2}$ and colloidal silica was used to coat paper sheets. The silica binder increased the adsorption capacities of $\mathrm{TiO}_{2}$ which enabled the photocatalyst to decompose textile dye in the wastewater $[59,60]$.

$\mathrm{TiO}_{2}$ nanowires were hydrothermally synthesized using $\mathrm{TiO}_{2}$ powders as a precursor for $24 \mathrm{~h}$ at $200^{\circ} \mathrm{C}$ followed by calcination process for $3 \mathrm{~h}$ at $400^{\circ} \mathrm{C}$. The incorporation of $\mathrm{TiO}_{2}$ nanowires in paper matrices by the hand sheet, resulting in agglomerated $\mathrm{TiO}_{2}$ nanowires (of length from 1 to $7 \mathrm{~mm}$ ) dispersed in paper fibers (Figure $10 \mathrm{~b}$ ). To avoid the agglomeration of $\mathrm{TiO}_{2}$ nanowires in the paper matrix, a tri-block copolymer Pluronic 123 (P123) was used, the hydrophilic end of this copolymer interacted with the $\mathrm{TiO}_{2}$ nanowires forming a layer on the surface of $\mathrm{TiO}_{2}$ nanowires. Consequently, incorporation of dispersed $\mathrm{TiO}_{2}$ nanowires (of diameter ranged from 20 to $40 \mathrm{~nm}$ ) in paper matrices were obtained as shown in (Figure 10 c) [61, 62].

\section{Layer by layer deposition}

Using the standard layer by layer deposition method, a wellorganized multilayer of linear polyelectrolyte and $\mathrm{TiO}_{2}$ were used to coat the cellulose fibers. The positively charged $\mathrm{TiO}_{2}$ nano-metal particles were mutually attached onto the surface of the cellulose fibers with the negatively-charged Poly (styrenesulfonate) (PSS), as shown in (Figure 11). So, some hydrogen bonding between cellulose fibers and $\mathrm{TiO}_{2}$ were replaced by the electrostatic attraction of the positive and negative polyelectrolyte fiber coatings, which may cause an increase in the paper strength properties i.e. increasing the thickness of the polyelectrolyte layer is improving the filler-fiber interactions 

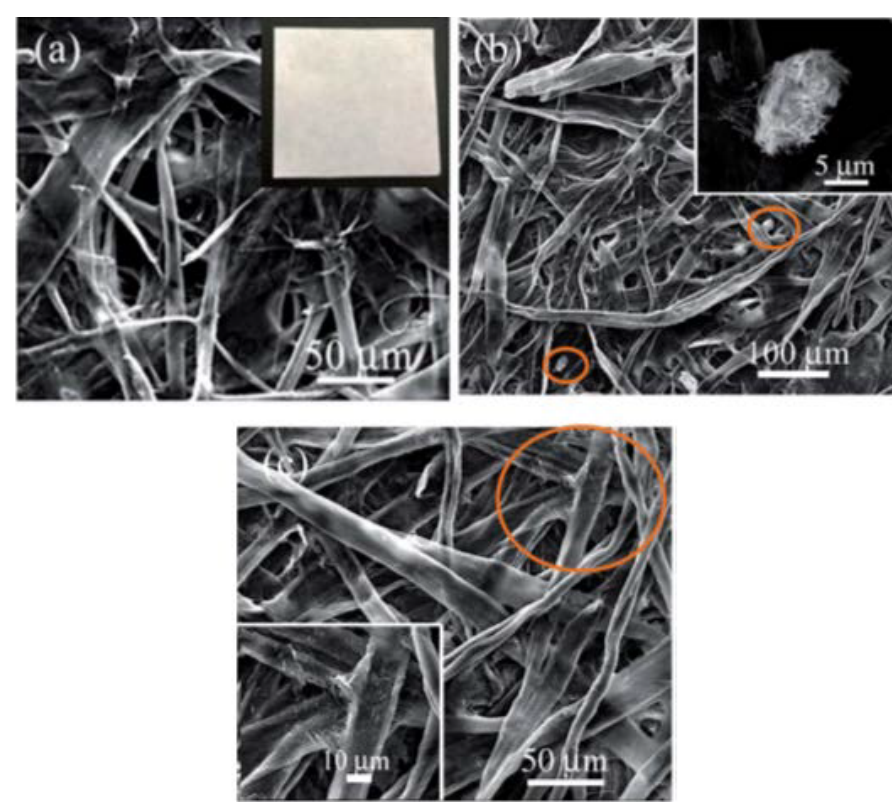

Figure 10. SEM images of paper matrices incorporated: (a) without $\mathrm{TiO}_{2} \mathrm{NWs}$, (b) with $\mathrm{TiO}_{2} \mathrm{NWs}$, and (c) with $\mathrm{TiO}_{2}$ NWs incorporated along with surfactant P123 [61]

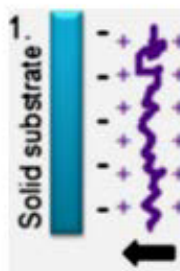

2.
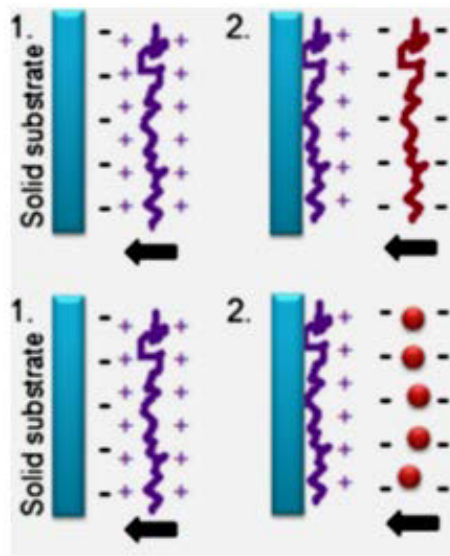

3.

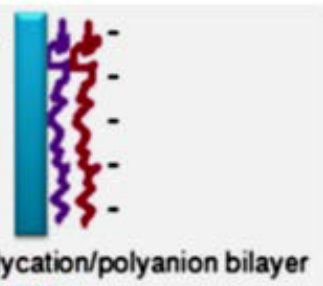

3.

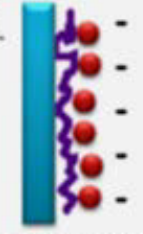

Nanoparticle/polyion bilayer
Figure 11. Layer-by-layer coating method [63].

and increasing the paper strength properties [63]. The layer by layer deposition technique have been applied in different applications, the following are some examples of these applications;

The paper sheets were coated with $\mathrm{ZnO}$ nano-metal particles and nanofibrillated cellulose NFC composite to study the antibacterial effects. To enable the formation of the $\mathrm{NFC/ZnO}$ (in range size 40.7 $\mathrm{nm}$ ), a modification of the surface of NFC should take place using both poly (diallyldimethylammonium chloride) and poly (sodium 4-styrenesulfonate) [4].

The synthesis and deposition of silica- Au nano-metal particles coat onto the cellulosic fibers substrate. In this technique, cellulose fibers were treated with polyelectrolytes to introduce cationic charge by alternative dipping in poly (diallyldimethylammonium chloride), poly (sodium 4-styrenesulfonate) and again in the poly (diallyldimethylammonium chloride) solutions. The treated cellulose fibers were then dipped in the $\mathrm{Au}$ colloids. Moreover, surface modifications of nano-metal particles with silica shells improves the optical properties and made these nanocomposites effective, especially in security paper production $[64,65]$.

\section{Sol- gel method}

The sol-gel method was used in the deposition of $\mathrm{TiO}_{2}$ onto cellulose fibers, where, negatively charged functional groups were introduced resulting in anchoring of the $\mathrm{TiO}_{2}$ on the cellulose matrix. The anchoring process is easy and reproducible technique, it is also can be used to produce self-cleaning, antimicrobial and photochromic surfaces [66]. The homogeneous distribution of $\mathrm{TiO}_{2}$ films on the surface of fibers led to the increase of the photo-degradation of the pollutant molecules. The $\mathrm{TiO}_{2}$ film is only photo-degrading the pollutant molecules, but not the cellulose fibers due to the complete adherences between the $\mathrm{TiO}_{2}$ film and the fibers which in turn protect the fibers from the attack by $\mathrm{O} 2-$ and $\mathrm{OH} \bullet$ species produced during light exposure.

\section{Direct assembly}

Au and Ag nano-metal particles are synthesized via citrate reduction of their aqueous salt solutions and then gathered directly onto the paper matrices, where the citrate group works as a reducing and stabilizing agent. The weakly bounded citrate ions import negative surface charges to the nano-metal particles which in turn incorporate these negative charges on the substrates through electrostatic self-assembly to avoid the agglomeration in solution [67]. The grafting of positively charged ammonium ions was produced through the electrostatic deposition of Au nano-metal particles onto the cotton's cationic cellulose. The $\mathrm{Au}$ nano-metal particles were directly assembled onto the cellulose substrate by immersing the cationic cellulose into a citrate-reduced $\mathrm{Au}$ colloidal solution. Increasing the citrate concentration enhanced the negative surface potential of $\mathrm{Au}$ nano-metal particles resulting in a higher packing density of Au nano-metal particles on the substrate [67].

Grafting of acrylamide onto bagasse paper sheets using potassium persulfate under the effect of microwave radiations (MWR) was precede. The Ag nano-metal particles are precipitated by reduction of silver nitrate on the acrylamide grafted bagasse paper matrices in the presence of citrate molecules as stabilizing agent as given in equation (10). Silver ions were stabilized through their electrostatic interactions with the electron-rich nitrogen atoms in the polyacrylamide grafted bagasse paper sheet. This is enabling them to be reduced at room temperature and be tightly established to the grafted bagasse paper matrices. So, the grafting of acrylamide onto bagasse paper sheet, followed by incorporation of $\mathrm{Ag}$ nano-metal particles leads to development of a novel biomaterial which elucidates fair biocidal action against $G$ +ve bacterium Staphylococcus aureus, G -ve bacterium $P$. aeruginosa, and yeast $C$. albicans. Paper sheets produced by this method can be used as an antibacterial packaging material to prevent food stuff from microorganism infection. This method can be applied for the manufacture of antibacterial food packaging material [68].

$$
4 \mathrm{Ag}^{+}+\mathrm{C}_{6} \mathrm{H}_{5} \mathrm{O}_{7} \mathrm{Na}_{3}+2 \mathrm{H}_{2} \mathrm{O} \longrightarrow 4 \mathrm{Ag}^{-}+\mathrm{C}_{6} \mathrm{H}_{5} \mathrm{O}_{7} \mathrm{H}_{3}+3 \mathrm{Na}^{+}+\mathrm{H}^{+}+\mathrm{O}_{2} \uparrow
$$

\section{In situ assembly}

Nano-metal particles are synthesized through either physical (thermal/UV) or chemical (sodium borohydride $\mathrm{NaBH}_{4}$ ) reduction methods. The physically synthesized nano-metal particles are uniform in shape and well distributed, whilst chemically synthesized nanometal particles are aggregates, both methods are used in different applications; e.g. antimicrobial paper is produced by physical methods 
(where well distribution of nano-metal particles is preferred), whilst a Surface Enhanced Raman Scattering (SERS) active substrate is produced by chemical methods (where aggregation of nano-metal particles is preferred) [69].

The in situ's synthesized $\mathrm{Au}$ nanoparticles are under carried a first immersion of cationic cellulose substrate into a sodium tetrachloroaurate dihydrate $\left(\mathrm{NaAuCl}_{4} \cdot 2 \mathrm{H}_{2} \mathrm{O}\right)$ solution, followed by immersion in a sodium borohydride $\left(\mathrm{NaBH}_{4}\right)$ solution to reduce the metal ions to zero-valence metal [67].

Using the in situ hydrothermal method, the incorporation of nano-metal particles on the paper matrices' cellulose fibers were achieved without using any retention aids, binders, or linkers [70]. In the presence of cellulose fibers, the hydrothermal treatment of $\mathrm{TiO}_{2}$ (diameter from 40 to $250 \mathrm{~nm}$ for $20 \mathrm{~h}$ at $150^{\circ} \mathrm{C}$ ), around $40 \%$ of the produced $\mathrm{TiO}_{2}$ were retained in the paper sheets, where, in the absence of cellulose fibers, $\mathrm{TiO}_{2}$ nanowires (diameter from 89 to $90 \mathrm{~nm}$ ) were gained. Consequently, one can obtain that the cellulose fibers play an important role in the control of the microstructure of the nano-metal particles [70]. The formation of covalent bonds between the cellulose fibers and the nano-metal particles were recognized in the in situ hydrothermal method. This method results in a high retaining percent of nano-metal particles in the paper fibers, creating available active sites for the applications. The addition of the retention aids enhanced the restriction of these active sites in the nanostructures; in addition, $\mathrm{TiO}_{2}$ nano-metal particles can nucleate, grow, and incorporate on the cellulose fibers surface. An interaction may take place between the hydroxyl groups (present on the surface of each of cellulose fibers) and the $\mathrm{TiO}_{2}$ nano-metal particles via $\mathrm{H}$-bonding, Figure 12 demonstrated the formation of permanent covalent bonds between $\mathrm{TiO}_{2}$ and cellulose fibers due to the dehydration process, which in turn lead to the growing of the $\mathrm{TiO}_{2}$ on the surface of the cellulose fibers [70]. Similarly, in situ hydrothermal procedure as discussed before for the incorporation of $\mathrm{TiO}_{2}$ nano-metal particles, Figure 13 demonstrated the incorporation of $\mathrm{ZnO}$ nanowires (of diameter ranged from 130 to $500 \mathrm{~nm}$ ) on the cellulose fibers surface via the hydrothermal method (for $14 \mathrm{~h}$ at $140^{\circ} \mathrm{C}$ ) using $\mathrm{ZnCl}_{2}$ as the $\mathrm{ZnO}$ precursor [71]. The mechanism of the incorporation of the $\mathrm{ZnO}$ nanowires was identical to the above discussed mechanism for incorporation of $\mathrm{TiO}_{2}$ nanoparticles.

Figure 14 schematically displays that, $\mathrm{ZnO}$ nano-metal particles of diameters $\sim 20 \mathrm{~nm}$ were coated on paper matrices using an ultrasound wave assisted process. The incorporation of $\mathrm{ZnO}$ nano-metal particles in the paper matrix depends on the sonication (time intervals from 5 to

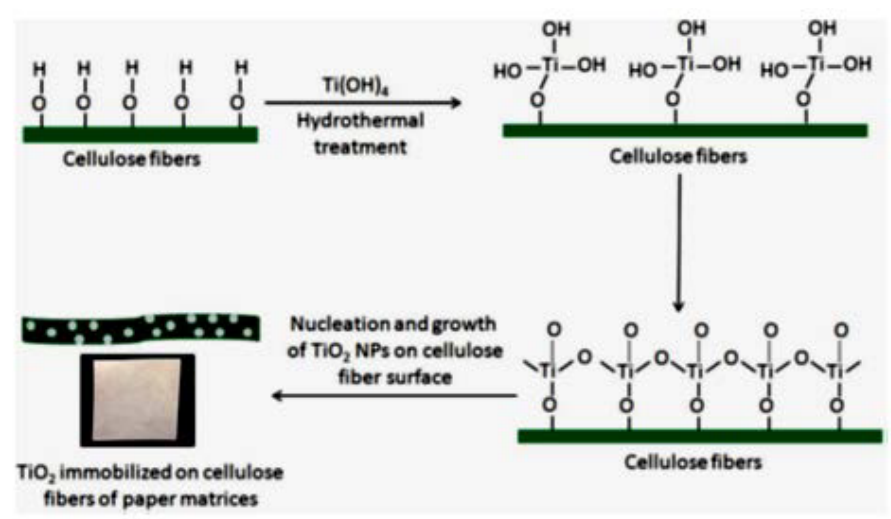

Figure 12. Mechanism for the nucleation, growth, and incorporation of $\mathrm{TiO}_{2}$ nano-metal particles on the surface of cellulose fibers of paper matrices [70]. (a)

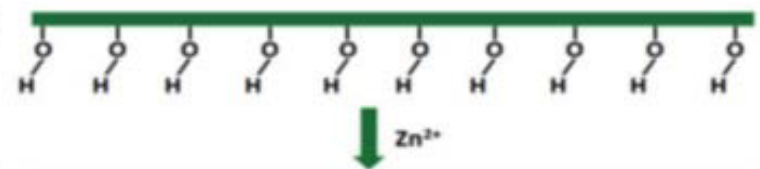

(b)

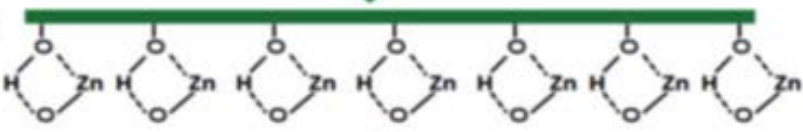

(c)

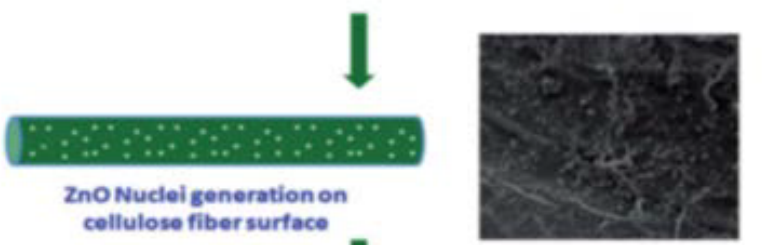

(d)
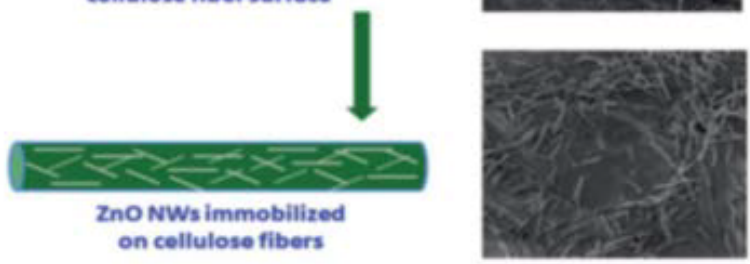

Figure 13. Mechanism for the nucleation and growth of $\mathrm{ZnO}$ nanowires on a cellulose fiber surface: (a) cellulose surface with hydroxyl groups, (b) interaction of $\mathrm{Zn}^{2+}$ with hydroxyl groups on a cellulose surface, (c) nucleation of $\mathrm{ZnO}$, and (d) growth of the $\mathrm{ZnO}$ nanowires [71].

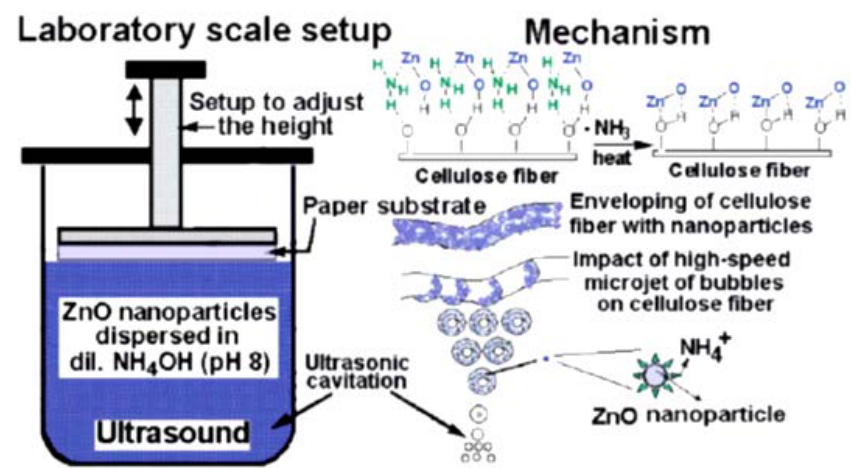

Figure 14. Schematic diagram representing the coating of $\mathrm{ZnO}$ nano-metal particles on the surface of a paper matrix by the sonication process [73].

$30 \mathrm{~min})$. It was found that, the maximum loading has slightly increased from (14.3 wt\%) at the starting $5 \mathrm{~min}$ of sonication to (17.7 wt\%) after 30 min of sonication a little increase in the loading occurred. Accordingly, the suitable sonication time to coat $\mathrm{ZnO}$ nano-metal particles in paper matrices is ranged from 10 to $20 \mathrm{~min}$. In addition, the $\mathrm{ZnO}$ nano-metal particles coated paper sheets has an antibacterial action against $E$. coli growth i.e., when the paper matrices was coated by $\mathrm{ZnO}$ nano-metal particles, the E. coli growth was reduced by an average of $99.99 \%$ [72].

Recently, the incorporation of saccharide capped- $\mathrm{ZnO}$ nanometal particles in paper fibers was reported and the antimicrobial actions were studied [73]. The saccharide capped $\mathrm{ZnO}$ nano-metal particles were synthesized by a microwave assisted technique using carbohydrates such as (glucose, g; sucrose, s; starch, st and alginic acid, aa), $\mathrm{Zn}\left(\mathrm{CH}_{3} \mathrm{COO}\right) 2.2 \mathrm{H}_{2} \mathrm{O}$ and $\mathrm{NaOH}$ solution (for $30 \mathrm{sec}$ at $800 \mathrm{~W}$ ). The results indicated that for $\mathrm{g}-\mathrm{ZnO}, \mathrm{s}-\mathrm{ZnO}$, st $-\mathrm{ZnO}$, and aa- $\mathrm{ZnO}$, the average particle sizes were $30.9 \mathrm{~nm}, 28.3 \mathrm{~nm}, 23.6$, and $19.0 \mathrm{~nm}$, respectively. The synthesized nano-metal particles were applied in 
paper making procedure. From all the treated paper matrices, aa- $\mathrm{ZnO}$ nano-metal particles indicated higher effectiveness in reducing about 86.06 and $81.71 \%$ of $E$. coli and S. aureus bacterial growth, respectively. Moreover, aa- $\mathrm{ZnO}$ nano-metal particles incorporated in paper matrices displayed antifungal action by inhibiting cellulose degradation using $G$. trabeum fungus. This is attributed to; aa- $\mathrm{ZnO}$ nano-metal particle has the smaller size compared to the other saccharide capped $\mathrm{ZnO}$ nanometal particles [74].

\section{Future outlook}

Due to the rapid changes in the technologies and the sacristy of raw materials, it was obligatory to maximize the usage of the present raw materials in producing new products using new techniques. Nanoscience has been applied in different ways to modify what we already have of raw materials to achieve new products of different usage. One of the applications that greatly made an advantage using the nanoscience is the development of paper based products for applications other than writing. Different thoughts had emerged about several materials with characteristics properties and microstructures to be used as fillers for development of papers for high end applications. This state of art reviews demonstrate the most recent researches of incorporating the nano-metal particles in paper matrix using the ex situ and in situ techniques. In ex situ method, the nano-metal particles were synthesized and then using the standard hand sheet making procedure, the paper matrices were incorporated by nano-metal particles. However, this method resulted in a retention problem, which was eliminated using the retention aids, flocculants and binders. On the other hand, the in situ method is a much easier method, where nanometal particles were synthesized and incorporated in paper matrices instantaneously. In conclusion, the in situ methods is more favorable than the ex situ methods due to the formation of the covalent bonds between nano-metal particles and cellulose which resulted in; higher retention percent, availability of nano-metal particles surfaces for different applications, uniform distribution of nano-metal particles on cellulose fibers surface. However, in situ methods have some challenges which could be overcome. One of these challenges is how to control the microstructure and crystallographic phases of the incorporated nano-metal particles, this challenge can be eliminated by fulfilling several studies to identify different parameters on the microstructures and obtaining the preferred crystallographic phase of the nano-metal particles. Another challenge of the generation of free radicles, due to the nano-metal particles embedded in paper matrices depolymerized cellulose fibers by time, led to the deterioration of the mechanical strength and the life time of paper sheets incorporated with nanometal particles. This deterioration challenge can be eliminated using the different retention aids to restrict the direct interactions between nano-metal particles and cellulose fibers surfaces, i.e., the generated free radicles cannot interact with cellulose fibers and the strength properties of paper matrices can be preserved.

From the previous discussion we can obtain that now a day, the scientific research using the nano-science have reached a new phase of development using different techniques to obtain different materials with different crystalline structure to be used in different application. However, new efforts should be exerted to decrease time, energy consumption, reaction steps and chemicals consumed in these techniques which in turn would decrease the consumption of resources and the environmental hazards.

\section{References}

1. Nikiforov A, Deng X, Xiong Q, Cvelbar U, Degeyter U, et al. (2016) Non-thermal plasma technology for the development of antimicrobial surfaces: a review. Journal of Physics D: Applied Physics 49: 204002-204009.

2. Sibhghatulla S, Shazi S, Adel MA, Syed MDR, Philip MR, et al. (2015) Nanobiotechnological approaches against multidrug resistant bacterial pathogens: an update. Curr Drug Metab 16: 362-370.1 [crossref]

3. Gliga AR, Skoglund S, Wallinder IO, Fadeel B, Karlsson HL (2014) Size-dependent cytotoxicity of silver nanoparticles in human lung cells: the role of cellular uptake, agglomeration and Ag release. Part Fibre Toxicol 11:1-17. [crossref]

4. Martins NCT, Freire CSR, Neto CP, Silvestre AJD, Causio J, et al. (2013) Antibacterial paper based on composite coatings of nanofibrillated cellulose and $\mathrm{ZnO}$, Colloids and Surfaces A: Physicochemical and Engineering Aspects 417: 111-119.

5. Bak T, Li W, Nowotny J, Atanacio AJ, Davis J (2015) Photocatalytic properties of TiO2: evidence of the key role of surface active sites in water oxidation. J Phys Chem A 119: 9465-9473. [crossref]

6. Sharma VK, Yngard RA, Lin Y (2009) Silver nanoparticles: green synthesis and their antimicrobial activities. Adv Colloid Interface Sci 145: 83-96. [crossref]

7. Jalal R, Goharshadi EK, Abareshi M, Moosavi M, Yousefi A, et al. (2010) ZnO nanofluids: green synthesis, characterization, and antibacterial activity. Materials Chemistry and Physics 121:198-201.

8. Cherif LY, Yahiaoui I, Aissani-Benissad F, Madi K, Benmehdi N, et al. (2014) Heat attachment method for the immobilization of $\mathrm{TiO} 2$ on glass plates: application to photodegradation of basic yellow dye and optimization of operating parameters, using response surface methodology, Industrial \& Engineering Chemistry Research, 53: 3813-3819.

9. Sakhawy ME, Hassan ML, Matouk H (2015) Semiconductor nanoparticles as surface coating for security papers, Nordic Pulp \& Paper Research Journal 30: 660-666.

10. Chauhan I, Aggrawal S, Mohanty P (2015) ZnO nanowire-immobilized paper matrices for visible light-induced antibacterial activity against Escherichia coli. Environmental Science Nano 2: 273-279.

11. Klajn R, Wesson PJ, Bishop KJ, Grzybowski BA (2009) Writing self-erasing images using metastable nanoparticle "inks". Angew Chem Int Ed Engl 48: 7035-7039. [crossref]

12. Tankhiwale R, Bajpai SK (2009) Graft copolymerization onto cellulose-based filter paper and its further development as silver nanoparticles loaded antibacterial food packaging material. Colloids Surf B Biointerfaces 69: 164-168. [crossref]

13. Zhang Y, Aslan K, Previte MJR, Geddes CD (2008) Metal-enhanced fluorescence from paper substrates: modified spectral properties of dyes for potential high throughput surface analysis and assays and as an anti-counterfeiting technology. Dyes and Pigments 77: 545-549.

14. Ngo YH, Li D, Simon GP, Garnier G (2012) Gold nanoparticle-paper as a threedimensional surface enhanced raman scattering substrate. Langmuir 28: 8782-8790. [crossref]

15. Zhao W, Ali MM, Aguirre SD, Brook MA, Li Y (2008) Paper-based bioassays using gold nanoparticle colorimetric probes. Anal Chem 80: 8431-8437. [crossref]

16. Ibrahim HMM (2015) Green synthesis and characterization of silver nanoparticles using banana peel extract and their antimicrobial activity against representative microorganisms. Journal of Radiation Research and Applied Sciences 8: 265-275.

17. Reddy SJ (2015) Silver nanoparticles - synthesis, applications and toxic effects on humans: a review. International Journal of Bioassays 4: 4563-4573.

18. Abbasi E, Milani M, Aval SA, Kouhi M, Akbarzadeh A, et al. (2016) Silver nanoparticles: synthesis methods, bio-applications and properties, Crit Rev Microbiol 42:173-180.

19. Özhava D, Kiliçaslan NZ, Özkar S (2015) PVP-stabilized nickel (0) nanoparticles as catalyst in hydrogen generation from the methanolysis of hydrazine borane or ammonia borane. Applied Catalysis B: Environmental 162: 573-582.

20. Espitia PJP, Soares NFF, Coimbra JSR, Andrade NJ, Cruz RS, et al. (2012) Medeiros, Zinc Oxide nanoparticles: synthesis, antimicrobial activity and food packaging applications. Food Bioprocess Technology 5:1447-1464.

21. Zeng H, Du XW, Singh SC, Kulinich SA, Yang S, et al. (2012) Nanomaterials via laser ablation / irradiation in liquid: a review. Advanced Functional Materials 22:1333-1353.

22. Mohamed MB, AbouZeid KM, Abdelsayed V, Aljarash AA, El-Shall MS (2010) Growth mechanism of anisotropic gold nanocrystals via microwave synthesis: formation of dioleamide by gold nanocatalysis. ACS Nano 4: 2766-2772. [crossref] 
23. Gouda M, Aljaafari A, Al-Fayz Y, Boraie WE (2015) Preparation and characterization of some nanometal oxides using microwave technique and their application to cotton fabrics. Journal of Nanomaterials 2015: 1-9.

24. El-Batal AI, El-Baz AF, Abo Mosalam FM, Tayel AA (2015) Gamma irradiation induced silver nanoparticles synthesis by monascus purpureus. Journal of Chemical and Pharmaceutical Research 5:1-15.

25. Bang JH, Suslick KS (2010) Applications of ultrasound to the synthesis of nanostructured materials. Adv Mater 22: 1039-1059. [crossref]

26. Li N, Zhao P, Astruc D (2014) Anisotropic gold nanoparticles: synthesis, properties, applications, and toxicity. Angew Chem Int Ed Engl 53:1756-1789. [crossref]

27. Liu S, Wang W, Chen J, Li JG, Li X, et al. (2015) Foamed single-crystalline anatase nanocrystals exhibiting enhanced photocatalytic activity. Journal of Materials Chemistry A 3: 17837-17848.

28. Arakha M, Saleem M, Mallick BC, Jha S (2015) The effects of interfacial potential on antimicrobial propensity of $\mathrm{ZnO}$ nanoparticle. Sci Rep 5: 9578. [crossref]

29. Gong X, Gu YQ, Li N, Zhao H, Jia C.-J (2016) Thermally stable hierarchica nanostructures of ultrathin MoS2 nanosheet- coated $\mathrm{CeO} 2$ hollow spheres as catalyst for ammonia decomposition. Inorg Chem 55: 3992-3999. [crossref]

30. Bang JH, Suslick KS (2010) Applications of ultrasound to the synthesis of nanostructured materials. Adv Mater 22: 1039-1059. [crossref]

31. Radzimska AK, Jesionowski T (2014) Zinc oxide-from synthesis to application: A Review. Materials 7: 2833-2881.

32. Dimitriev Y, Gancheva M, Iordanova R (2011) Synthesis of ZnO by mechanochemica decomposition of zinc carbonate hydroxide. Journal of the University of Chemical Technology and Metallurgy 46: 243-248.

33. Hoeng F, Denneulin A, Bras J (2016) Use of nanocellulose in printed electronics: a review. Nanoscale 8: 13131-13154. [crossref]

34. Barud HS, Regiani T, Marques RF, Lustri WR, Messaddeq Y, et al. (2011) Antimicrobial bacterial cellulose-silver nanoparticles composite membranes. Journal of Nanomaterials 2011: 1-10.

35. Chen M, Kang H, Gong Y, Guo J (2015) Bacterial Cellulose Supported Gold Nanoparticles with Excellent Catalytic Properties. ACS Appl Mater Interfaces 7: 21717-21726. [crossref]

36. Zhang T, Wang W, Zhang D, Zhang X, Ma Y, et al. (2010) Biotemplated synthesis of gold nanoparticle-bacteria cellulose nanofiber nanocomposites and their application in biosensing. Advanced Functional Materials 20: 1152-1160.

37. Kaushik M, Moores A (2016) Review: nanocelluloses as versatile supports for metal nanoparticles and their applications in catalysis. Green Chemistry 18: 622-637.

38. Hebeish A, Farag S, Sharaf S, Shaheen TI (2015) Nanosized carbamoylethylated cellulose as novel precursor for preparation of metal nanoparticles. Fibers and Polymers 16: 276-284.

39. Drogat N, Granet R, Sol V, Memmi A, Saad N (2011) Antimicrobial silver nanoparticles generated on cellulose nanocrystals. Journal of Nanoparticle Research 13:1557-1562.

40. Chen L, Cao W, Quinlan PJ, Berry RM, Tam KC (2015) Sustainable catalysts from gold loaded polyamidoamine dendrimer-cellulose nanocrystals. ACS Sustainable Chemistry \& Engineering 3: 978-985.

41. Jiao L, Ma J, Dai H (2015) Preparation and Characterization of Self-Reinforced Antibacterial and Oil-Resistant Paper Using a NaOH/Urea/ZnO Solution. PLoS One 10: e0140603. [crossref]

42. Behnajady MA, Eskandarloo H, Modirshahla N, Shokri M (2011) Investigation of the effect of sol-gel synthesis variables on structural and photocatalytic properties of TiO2 nanoparticles. Desalination 278:10-17.

43. Saha K, Agasti SS, Kim C, Li X, Rotello VM (2012) Gold nanoparticles in chemical and biological sensing. Chem Rev 112: 2739-2779. [crossref]

44. Martini E, Tomassetti M, Campanella L, Fortuna A (2013) Reducing the pollutant load of olive mill wastewater by photocatalytic membranes and monitoring the process using both tyrosinase biosensor and COD test. Front Chem 1: 1-8. [crossref]

45. Domaradzki J, Mazur M, Sieradzka K, Wojcieszak D, Adamiak B (2013) Photocatalytic properties of Ti-V oxides thin films. Optica Applicata 43: 153-162.

46. Patzke GR, Zhou Y, Kontic R, Conrad F (2011) Oxide nanomaterials: synthetic developments, mechanistic studies, and technological innovations. Angew Chem Int Ed Engl 50: 826-859. [crossref]
47. Gupta SM, Tripathi M (2012) A review on the synthesis of TiO2 nanoparticles by solution route. Central European Journal of Chemistry 10: 279-294.

48. Wang Y, He Y, Lai Q, Fan M (2014) Review of the progress in preparing nano TiO2: An important environmental engineering material. J Environ Sci (China) 26: 2139 2177. [crossref]

49. Mohapatra M, Anand S (2010) Synthesis and applications of nano-structured iron oxides/hydroxides. International Journal of Engineering. Science and Technology 2:127-146.

50. Gentzen M, Habicht W, Doronkin DE, Grunwaldt JD, Sauera J, et al. (2016) Bifunctional hybrid catalysts derived from $\mathrm{Cu} / \mathrm{Zn}$ based nanoparticles for single-step dimethyl ether synthesis. Catalysis Science \& Technology 6: 1054-1063.

51. Salman JAS, Ibrahem KH, Ali FA (2014) Effect of culture media on biosynthesis of titanium dioxide nanoparticles using Lactobacillus crispatus. International Journal of Advanced Research 2:1014-1021.

52. Dehnad A, Hamedi J, Khadivi FD, Abusov R (2015) Green Synthesis of gold nanoparticles by a metal resistant arthrobacter nitroguajacolicus isolated from gold mine. IEEE Trans Nanobioscience 14: 393-396. [crossref]

53. Hasan S (2015) A Review on nanoparticles: their synthesis and types. Research Journal of Recent Sciences 4: 9-11.

54. Nestor ARV, Mendieta VS, Lopez MAC, Espinosa RMG, Lopez MAC, et al. (2008) Solventless synthesis and optical properties of $\mathrm{Au}$ and $\mathrm{Ag}$ nanoparticles using camellia sinensis extract. Materials Letters 62: 3103-3105.

55. Ngo YH, Li D, Simon GP, Garnier G (2011) Paper surfaces functionalized by nanoparticles. Adv Colloid Interface Sci 163: 23-38. [crossref]

56. Joshi KM, Patil BN, Shrivastava VS (2011) Preparation, characterization and applications of nanostructure photocatalysts. Archives of Applied Science Research 3:596- 605 .

57. Shen J, Song Z, Qian X, Ni Y (2011) A review on use of fillers in cellulosic paper for functional applications. Industerial \& Engineering Chemistry Research 50: 661-666.

58. Adel AM, Ahmed NM, Diab MA, Selim MM (2016) The influence of TiO2/CC core/ shell pigments on the properties of paper sheets. Powder Technology 291: 437-447.

59. Alimoradzadeh R, Assadi A, Nasseri S, Mehrasbi MR (2012) Photocatalytic degradation of 4-chlorophenol by UV/H2O2/NiO process in aqueous solution. Iranian J Environ Health Sci Eng 9: 1-8. [crossref]

60. El-Sherbiny S, Morsy F, Samir M, Fouad OA (2014) Synthesis, characterization and application of $\mathrm{TiO} 2$ nanopowders as special paper coating pigment. Applied Nanoscience 4: 305-313.

61. Chauhan I, Chattopadhyay S, Mohanty P (2013) Fabrication of titania nanowires incorporated paper sheets and study of their optical properties. Materials Express 3: 343-349.

62. B. Zhao and Z. Shao (2012) From Paper to Paper-like hierarchical anatase TiO2 Film Electrode for high-performance lithium-ion batteries. The Journal of Physical Chemistry C 116: 17440-17447.

63. Candan C (2011) Nano-hybrid surface coatings on uncoated papers from softwood fibers and wood free fibers and printability. Asian Journal of Chemistry 23: 3747- 3754

64. Pinto RJB, Marques PAAP, Martins MA, Neto CP, Trindade T (2007) Electrostatic assembly and growth of gold nanoparticles in cellulosic fibres. Journal of Colloid and Interface Science 312: 506-512.

65. Pulit J, Banach M (2014) Preparation of nanosilver and nanogold based on dog rose aqueous extract. Bioinorg Chem Appl 2014: 658935. [crossref]

66. Amin MSA, Uddin MJ, Islam MA (2012) Removal of azo dye by synthesized TiO2 nanoparticles. Nanomaterials and the Environment 1: 18-22.

67. Dong H, Hinestroza JP (2009) Metal nanoparticles on natural cellulose fibers: electrostatic assembly and in situ synthesis. ACS Appl Mater Interfaces 1: 797-803. [crossref]

68. Kamel S (2012) Rapid synthesis of antimicrobial paper under microwave irradiation Carbohydr Polym 90: 1538-1542. [crossref]

69. Anouar M, Jbilat R, Borgne VL, Ma D, Khakani MAEl (2016) Ag nanoparticledecorated single wall carbon nanotube films for photovoltaic applications. Materials for Renewable and Sustainable Energy 5: 1-9.

70. Chauhan I, Mohanty P (2015) In situ decoration of TiO2 nanoparticles on the surface of cellulose fibers and study of their photocatalytic and antibacterial activities Cellulose 22: 507-519. 
71. Thakur S, Barua S, Karak N (2015) Reduced graphene oxide-metal oxide nanohybrid for efficient adsorption, photodegradation and photoinactivation of chemical and microbial contaminants. Journal of Nanotechnology in Diagnosis and Treatment 3: 12-22.

72. Abramova AV, Abramov VO, Gedanken A, Perelshtein I, Bayazitov VM (2014) An ultrasonic technology for production of antibacterial nanomaterials and their coating on textiles. Beilstein J Nanotechnol 5: 532-536. [crossref]
73. Ghule K, Ghule AV, Chen BJ, Ling YC (2006) Preparation and characterization of $\mathrm{ZnO}$ nanoparticles coated paper and its antibacterial activity study. Green Chemistry 8: 1034-1041.

74. Khatri V, Halasz K, Trandafilovic LV, Dimitrijevic- Brankovic S, Mohanty P, et al (2014) ZnO-modified cellulose fiber sheets for antibody immobilization. Carbohydr Polym 109: 139-147. [crossref]

Copyright: (C2016 Adel AM. This is an open-access article distributed under the terms of the Creative Commons Attribution License, which permits unrestricted use, distribution, and reproduction in any medium, provided the original author and source are credited. 